\title{
Fabian Kindermann
}

\section{Humankapital, Einkommensunsicherheit und öffentliche Finanzpolitik}

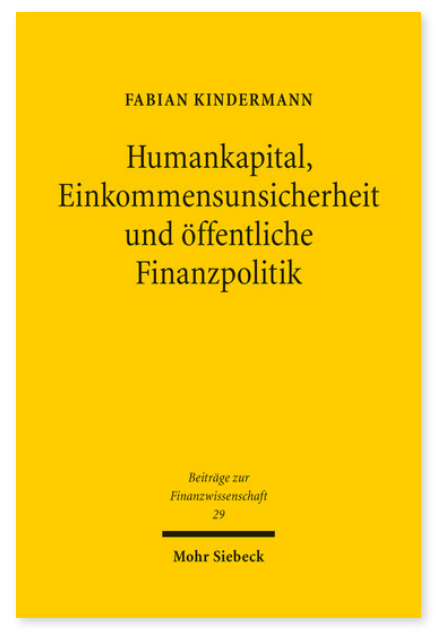

2012. XI, 161 Seiten. BtrFin 29

SBN 978-3-16-152296-3

DOI 10.1628/978-3-16-152296-3

eBook PDF $74,00 €$

ISBN 978-3-16-152256-7

fadengeheftete Broschur $74,00 €$
Fabian Kindermann analysiert die Wirkungen öffentlicher Finanzpolitik in allgemeinen Gleichgewichtsmodellen mit überlappenden Generationen. Das von ihm verwendete Simulationsmodell erweitert die Literatur dahingehend, dass Haushalte ihr Humankapital sowohl über formale Bildung als auch über Weiterbildungsmaßnahmen vermehren können. Individuelle Entscheidungen werden unter einer Reihe von Unsicherheiten und Marktunvollkommenheiten getroffen. In diesem Kontext werden folgende Fragestellungen untersucht: Sollte der Staat universitäre Bildung aus Steuermitteln bereitstellen oder sollte die Bildungsfinanzierung den Studierenden obliegen? Welchen Einfluss haben Rentenreformen auf die individuelle Bildungsentscheidung? Und: Wie sollte ein Einkommensteuersystem ausgestaltet sein, das positive Umverteilungseffekte und negative Verzerrungseffekte bei Arbeitsangebot und Humankapitalbildung in Einklang bringt?

Fabian Kindermann Geboren 1984; 2008 Diplom-Wirtschaftsmathematiker; 2008-12 Wissenschaftlicher Mitarbeiter am Lehrstuhl für Finanzwissenschaft an der Universität Würzburg; 2012 Promotion; von Oktober 2012 bis September 2013 Forschungsaufenthalt an der Northwestern University, Evanston, IL, USA.
Jetzt bestellen:

https://mohrsiebeck.com/buch/humankapital-einkommensunsicherheit-und-oeffentliche-finanzpolitik-9783161522963? no_cache=1

order@mohrsiebeck.com

Telefon: +49 (0)7071-923-17

Telefax: $+49(0) 7071-51104$ 